\title{
CORRESPONDENCE
}

\section{Breton Tombs}

SiR,-In "Breton Origin for Tombs" (Nature, 228, 1019; 1970) several radiocarbon-14 dates are given in terms of absolute ages BC. I should hope your archaeological correspondent knows, and you should editorially recognize the fact, that radiocarbon-14 determinations do not produce results of this kind. Any determination is measured in years before present (BP, $P$ being $A D$ 1950) and has a standard deviation (for example, $5340 \pm$ 250). The most accurate general usage of this should employ two standard deviations, that is, $4840-5840 \mathrm{BP}$ or, if $\mathrm{BC}$ terms must be used, 2890-3890 BC.

Additionally, of course, radiocarbon years are not equivalent to calendar years, as recent tree-ring research is demonstrating. Renfrew ${ }^{1}$ gives a useful review of this problem and its application to European prehistory in the period discussed by your correspondent, who seems to be somewhat behind the times (in publication years).

\section{Yours faithfully,} J. Peter White

Department of Anthropology,

University of California,

Berkeley 94720

'Renfrew C. A., World Archaeology, 2, 199 (1970).

THis letter has been shown to our correspondent, who replies:

Since the work of Stuiver and Suess in 1966 (Radiocarbon, 8, 543), it has been clear that radiocarbon dates are only relative dates which require calibration. Despite the implied optimism of $\mathrm{Mr}$ White (and of Dr Renfrew), the accurate calibration of radiocarbon dates remains a task for the future. A more recent article by Renfrew which may not yet have reached $\mathrm{Mr}$ White is in the Proceedings of the Prehistoric Society $(36,280 ; 1970)$; there is an authoritative review by Suess in Radiocarbon Variations and Absolute Chronology (Proceedings of the Twelfth Nobel Symposium) (edit. by I. U. Olssen) (Wiley, 1970) When comparing dates within Europe, it remains most convenient to quote uncalibrated dates on the 5568 half-life. Whether these are expressed in years BP or BC makes not a fig of difference.

Certainly, the standard deviation of all dates should be considered $( \pm 2 \sigma$ giving about a $95 \%$ probability that the true age lies within the zone defined). The standard deviation relates only to counting error, however, and does not take into consideration other equally important potential error sources.

The essential point of my article was that the emerging pattern of radiocarbon dates for Breton passage graves sets them markedly earlier than elsewhere in Europe.

So far the Breton passage grave dates are 800 years and ten standard deviations earlier than any elsewhere. This difference and the merging pattern suggest the possibility of an independent origin of passage graves in Brittany. It remains perfectly possible, pace $\mathrm{Mr}$ White, that the earliest Neolithic settlers in England (earliest English Neolithic dates: $3390 \mathrm{BC} \pm 150$ for Cissbury (BM-181) and 3505 BC \pm 120 for Shippea Hill (Q-584) ) were aware of Breton customs of collective burial and megalithic architecture.

\section{Freezer Failure}

SIR,-I wish to report the successive failure of no less than six ultra-low temperature electrical freezers from the same manufacturer. There are few calamities in a biological research laboratory worse than the thawing of such freezers in which are stored purified viruses, tissue culture cells, cell extracts, and purified enzymes. We have suffered considerable loss and inconvenience from these incidents, and wish to warn others of these problems.

The first of these freezers was installed in May 1969; it worked for only seven months. One compressor developed a short circuit, causing the contents of the freezer to thaw. After three months of attempting to fix the instrument (during which time we were of course severely hampered) the manufacturers determined that it could not readily be repaired. They loaned us a temporary replacement model, and agreed to provide us with a permanent replacement. The temporary freezer functioned for two months, then developed a leak in the refrigeration system and warmed up. Fortunately, by this time our permanent replacement had arrived, and was immediately connected in its place. This new freezer worked for three months, and then failed (apparently also due to a leak in the refrigeration system). The loss of several thousand dollars' worth of tumour viruses and enzyme preparations was narrowly averted because we were able to obtain some space in an older freezer which apparently had been functioning normally for several years. However, the automatic alarm system for power failure proved to be defective. This quasi-reliable instrument thawed when the power was inadvertently disconnected by maintenance personnel.

Two other freezers were installed in May 1970 in another laboratory of this department. One worked for one month, failed for several months, and is only now working properly. The other did not work when installed and was made operative only several months later. Their futures remain in continuous doubt.

Yours faithfully,

HARVEY F. Lodish

Massachusetts Institute of Technology,

77 Massachusetts Avenue,

Cambridge,

Massachusetts 02139

\section{Obituary}

\section{Sir Christopher Ingold}

Sir Christopher INGOLD died on December 8, 1970, at the age of seventy-seven. The classifications, concepts and terminology which he introduced provided the framework for the theory of reaction mechanisms and influenced profoundly the development of chemistry as a whole.

Christopher Kelk Ingold was born in London on October 28, 1893. He chose to study chemistry, in spite of a characteristically strong interest in physics, and took his first degree at University
College, Southampton. He went on to do research with J. F. Thorpe at Imperial College, leaving in 1918 to spend two years as a research chemist with Cassel Cyanide in Glasgow. He then returned to Imperial College in 1920 and four years later he was elected a Fellow of the Royal Society and appointed Professor of Organic Chemistry at the University of Leeds. He became Professor of Chemistry at University College, London, in 1930 and Director of Laboratories there in 1937. From 1939 to 1944 his department was in evacuation at Aberystwyth. As soon as the war ended he began re-establishing international links and quickly built up the department again, attracting research workers from all over the world. He was appointed Professor Emeritus on his retirement in 1961.

The contributions which Ingold made to chemistry were recognized by many honours and awards. The Chemical Society awarded him the Longstaff Medal (1951) and the Faraday Medal (1962). The American Chemical Society awarded him the James Flack Norris award (1965). The Royal Society awarđed him the Davy Medal (1946) 